\title{
Young women's experiences with breast cancer: An imperative for tailored information and support
}

by Margaret I. Fitch, R.E. Gray, R. Godel and M. Labrecque Abstract

This work was undertaken to provide a basis for determining the type of assistance young women living with breast cancer would find useful. In-depth interviews were conducted with 28 women diagnosed with breast cancer before the age of 45 years about their experiences with breast cancer. They ranged in age from 28 to 42 years at the time of diagnosis. Three overarching themes emerged from the analysis- "everything depends on acting now," "everything is out of sync," and "cancer invaded my whole life." These women shared perspectives similar to those of older women, but also held perspectives unique to being young, with young families and busy career lives. Many found services did not match their requirements and they urged the creation of services tailored to their unique needs.

A diagnosis of breast cancer is difficult for a woman, regardless of her age (Trussler, 2001). In Canada, many resources exist to help women meet their information and support needs during breast cancer. However, few services are specifically designed for women of specific ages. Annually, 22,200 women are diagnosed with breast cancer (NCIC, 2006). Seventeen per cent are under the age of 50 at diagnosis and breast cancer is the leading cause of death for women between 35 and 50 . These women are often diagnosed with a highergrade neoplasm than older women and the therapy for this lesion is aggressive. This cohort of women may have unique needs and benefit from programs designed to meet these needs.

Being a young woman often means having a busy life balancing family and career demands. Women talk about juggling a variety of roles and responsibilities during this time of their lives (Turner, 1990). For many, there is a felt pressure to put other family member needs ahead of caring for oneself. Women express the view, "there is no time for a Mom to get sick" (Fitch, Bunston, \& Elliott, 1999).

The cohort of women who are currently between 35 and 50 years have several unique characteristics. They are, on average, well educated and have been exposed to more societal freedoms and career opportunities than their predecessors (Evans \& Avis, 1999; Turner, 1990). Many have postponed marriage or having children until in their thirties. They often have young children at home at the very time aging parents need more assistance or become ill. This age cohort also has had a pattern of speaking out about issues and being politically active (Anderson, 1991). A large proportion has paid employment outside the home and is engaged in career-building activities (Finlayson, 1995). Additionally, the proportion of single women in this cohort is larger than was previously the case (Anderson \& Stewart, 1994). Women are choosing not to marry or are electing to be single parents. Developing services for this cohort of women if they develop breast cancer requires a clear understanding of their specific needs and how best to tailor the service delivery.

\section{Background literature}

There is relatively little research on the supportive care needs and experiences of young women diagnosed with breast cancer. The needs of women facing a breast cancer diagnosis and living with the aftermath of treatment have received considerable attention by both quantitative and qualitative investigators (Hilton, 1996; Bilodeau \& Degner, 1996; Rondle, 1997; Rees \& Bath, 2000; Brown, Koch, \& Webb, 2000; Nissen, Swanson, \& Kind, 2002; Raupach \& Hiller, 2002; Bock et al., 2004; Davis, Williams, Parle, Redman, \& Turner, 2004). Clearly, a breast cancer diagnosis and treatment have physical, social, emotional, psychological and spiritual consequences. The events not only have an impact on the woman, but also on the family members (Yates, 1999; Lewis, 2004). During the past 15 years, there has been a substantial increase in the body of knowledge about the impact of breast cancer on male partners and on children (Quinn-Beers, 2001; Kristjanson, Chalmers, \& Woodgate, 2004; Hilton, Crawford, \& Tarko, 2000; Lethborg, Kissane, \& Burns, 2003). Despite this amount of investigation, young women's supportive care needs have not been clearly described.

\section{Purpose}

Members of breast cancer support groups have raised concerns about the lack of support services specifically designed for young women with breast cancer (Ontario Breast Cancer Information Exchange Stakeholder Forums, 2001). This research was undertaken to provide a basis for understanding what services ought to be designed for young women. The specific purpose of the research was to explore the experiences and perspectives of young women who had been diagnosed and treated for breast cancer.

\section{Methods}

This study used in-depth interviews to gain a better understanding of the experiences and perspectives of young women regarding breast cancer who were 45 years of age or younger at the time of diagnosis. The open-ended interviews allowed the participants to talk about the events surrounding the diagnosis and treatment of the disease and their responses to those events.

As part of a cancer registry-based study concerning the utilization of support services for breast cancer, women were asked if they would be willing to be contacted for an interview (Gray et al., 2000). A random selection of women was made from those who agreed to be contacted and who met the age and language criteria (45 years of age or less at the time of initial breast cancer diagnosis; English speaking). A letter of invitation for this qualitative interview was sent to the selected women with telephone follow-up two weeks later. The telephone call provided an opportunity to clarify the women's questions about the interview and determine their willingness to participate. The women who consented were interviewed over the

Margaret I. Fitch, Head, Oncology Nursing and Supportive Care, Toronto-Sunnybrook Regional Cancer Centre, Toronto, ON, marg.fitch@sunnybrook.ca 
telephone at a time convenient for them. The interviews were audiotaped and followed the interview guide created for the study. The guide was piloted with two young women prior to launching the full study. The interviews were conducted by a research assistant highly skilled in this type of data collection and lasted between 45 and 95 minutes. The interview guide used open-ended questions to stimulate description of the events surrounding the diagnosis and treatment of the breast cancer, the woman's responses to the events, challenges or impacts she experienced, how she managed those challenges, and what supports she thought young women needed. Probes were used only as encouragers (i.e., tell me a little more about that), or for clarification (e.g., did that happen before or after your surgery?).

The audiotapes were transcribed verbatim and identifying features were removed. A content and theme analysis was performed (Silverman, 2000). Each team member independently read each transcript and made marginal notes about the content. Team members discussed their impressions of the content and designed an overall categorization scheme for the content. One investigator then completed all the coding according to the agreed-upon categorization scheme (MF). The content within each category was then reviewed and summarized. The key ideas unique to young women were identified by the team and resulted in three overarching, equally prominent, themes being identified. The team identified the three themes by discussing the coded interview content together. Throughout the analysis, the emphasis was to isolate the specific considerations for young women experiencing breast cancer (i.e., what was unique for their age group). This was done by the team members, who have specific expertise in research related to the experiences of women with breast cancer, discussing and agreeing upon what was unique to the younger women's experiences from those described previously in the research and literature.

\section{Findings}

\section{Selected characteristics}

The 28 young women who were interviewed for this investigation willingly offered rich, insightful narratives. The women ranged in age from 28 to 42 years at the time of the diagnosis. They were between three and four years since their original diagnosis of breast cancer (average $=3.8$ at the time of the interview). Five had experienced a recurrence and were receiving treatment at the time of the interview. All had surgery and radiation or chemotherapy or a combination of both treatments.

\section{Context of the interviews}

Throughout the interview, these young women spoke in a forthright manner, providing detailed descriptions about their experiences. Even four years after the diagnosis, the intensity of their emotional responses was clearly evident during the interviews. Many cried during the telling of particularly painful experiences. They commented that the timing of the interview was very likely good for them in that they were able to look back and reflect on what had happened in a different way than if the interview had occurred when they were first diagnosed, or in the middle of their treatment. Several thought they likely could not have gone through the interview sooner because the experiences were too painful to talk about at the time they were happening. They thought that having some distance from the events, and having some experience talking about those events with others (albeit family, friends, or peers) helped them feel ready to do the interview. All expressed a desire to participate in the interview in order to make things better for other young women who are diagnosed with breast cancer in the future.

Without exception, these young women talked about the tremendous shock and dismay of the diagnosis and the challenges they experienced undergoing treatment. Many issues they described reflected the types of issues and events described by other and older breast cancer survivors (e.g., waiting, telling others, impact on family, communication with physicians, and dealing with uncertainty) (Trussler, 2001). However, during the interviews, it became evident that several dimensions coloured their experiences and influenced their perspectives. The dimensions included whether they were single or partnered, did or did not have children, had young children or adolescents, were working outside of the home, had access to financial resources, and the actual treatment required for their stage of disease. These dimensions influenced the types of events that occurred and shaped the perceptions the women held about their breast cancer experience. They described their concerns and worries in light of their personal commitments and what was important to them individually. The aggressive radiation and chemotherapy regimens demanded these women to be present at the cancer facility and imposed certain side effects, both of which interfered with the ability to engage in daily activities and fulfill roles and responsibilities.

\section{Theme: Everything depends on acting now}

The young women interviewed for this study expressed an overwhelmingly intense drive to live. They were prepared to do whatever it took to stay alive and had little patience for waiting. They wanted to act quickly and to take the necessary steps immediately to protect or ensure their future. Without immediate action, they believed their future might not exist. The thought that they might not have a future caused feelings of panic, fear, and dread and resulted in an intense drive to take actions that would ensure their survival.

My main concern was taking care of myself, making myself healthy so that I'm here for my family. That's exactly what I did. (27)

...my diagnosis wasn't great. It was very aggressive because of my age and other issues, and there was node involvement. So, I didn't have a particularly good prognosis...we needed something aggressive. We were going to, we were prepared to do whatever it took. I was prepared to do whatever it took, whatever I needed to do. (12)

Each woman described reasons she had for wanting to live and not have her life cut short-to be present for children and partners, to reach a goal, to make a significant contribution. A sense of anger and outrage with the unfairness of a cancer diagnosis at a young age often came spilling out during the interviews. These young women had so many things to do yet in their lives and to not be able to do them was unthinkable.

...I'm divorced and my two children... I was more concerned about them than about me... [I thought] I have to beat this. I have to beat this for my kids...all I wanted to do was survive. (26)

My biggest fear was that I'd never see tomorrow... that I'd never get a chance to watch my two kids grow up. (2)

A sense of urgency emerged for these women around the challenge of sorting out exactly what needed to be done to ensure the desired future. There was a perceived challenge in getting the right treatment, getting the necessary information and support, changing one's lifestyle, and making the best choices. Each decision that was made was aimed toward the goal of staying alive. Each woman felt the need to figure out for herself what was important and necessary for her to accomplish that goal.

For younger women, so much is at stake. It's changing their lives. They need to get the right information, up front. If they plan to have children they need to know about it all before treatment, not just find out afterwards that they can't. (20)

[most difficult?] Making the decision about what to do... just the decision-making... it was really hard to think about... I was only 28. It's a lot to think about. (10)

Repeatedly, the young women talked about the necessity of putting one's own needs first as a vitally important step to cope with, and to conquer the disease. However, they found it was also one of the most 
challenging things for them to do. Children's and partners' needs so often dominated their daily lives. To not be available to meet the needs of children or partners engendered a great deal of guilt for these women. Yet, they expressed the belief that protecting oneself and recovering from cancer required looking after oneself first and foremost. Learning how to do that was of utmost importance for them, yet very much of a struggle. Many women said the most valuable learning for them had been to put themselves on their own priority list and learn how to be skillful in negotiating ways to meet their own needs. They learned about prioritizing the self as being of value and finding balance.

I had to try and do the minimum that I could do, but at the same time, not to neglect the children...to tell the children to stay away from me because mummy could get sick, it was already so hard... they were used to seeing me around and doing everything... all of a sudden Mummy disappears from their lives. The children felt it and I felt that. They felt that they were not rejected, but certainly neglected. (14)

There's a lot of adjusting, you know...like the house not being what you'd like it to be...or the garden not being what I'd like it to be...you have to rely on others... and I am not used to that. I am pretty independent and that was hard, relying on others. (16)

Another necessity for these women was to remain "upbeat" and positive. They felt much uncertainty about the cancer and treatment and experienced a pervasive sense of fear about recurrence. Instead of dwelling on the uncertainty and the fear, these young women felt they needed to work at finding the positive, to be positive, and work intensely hard to keep things within their families as normal as possible. They did not want their illness to create a major upheaval for children or create problems that would have future implications.

I don't think I ever passed my fear of cancer on to them. I was always very positive. (7)

I needed the whole experience to affect my children as little as possible. And...it did not overly affect them. They were still doing all the things...that was important. We are a routine household. I needed that to continue for my own self, too, to stay the course. (19)

I really wanted to ensure that everything was normal... everything would go on the same as ever... I didn't want them [children] to feel they had to stop what they were doing. (18)

A mental fatigue accompanied the efforts of these young women who felt such an intense drive to keep going and do what they felt needed to be done. There was a toll on them for keeping the emotions in check and preventing them from spilling over; in balancing the needs of their family, their careers, and themselves; in staying on top of new information about breast cancer and treatment so as not to miss something important for their survival, and in not resigning to the spectre of their own mortality.

You sort of think, I can control this, I can be strong... I can do this myself... and it's because you are so totally unaware of the feelings and what's going to hit you... so you figure you can do it. And then one morning you wake up in tears. (7)

For all, this diagnosis was the first time they had been brought face-to-face with the possibility of their own death. They first thought the cancer meant death, if not now, then in the near future. Four years after that initial brush with the notion of dying, they were now waiting for what they felt could be their second-the five-year survival mark was looming like a dark cloud on the horizon. Many felt they were holding their breath, waiting to reach that mark without recurrent disease rearing its head. These women harbored a strong belief that the five-year mark of being cancer-free was a time for celebration, and embraced a sense that everything would be fine if they reached that point.

What's most challenging is the uncertainty-if you're really over it...recurrence...it's hanging over your head. You don't know if you're going to face a recurrence (24).
It's been four years and, in some ways, it's harder now. I mean, you don't get a recurrence two weeks after treatment... but now could be the time, three to five years. Subconsciously it's always there... it weighs heavily now. I'm starting to see other women in the group who were diagnosed the same time as I was... and they are, some of them, having recurrences. It really scares the crap out of you. (19)

... with the others in my family, including my husband, they think it's all over. It's done, you know. Just get over it. Whereas for me, it's always a possibility at the back of my mind, that a recurrence could occur. (6)

\section{Theme: "everything is out of sync"}

The second overarching theme centred on the notion that what was happening to these women was not supposed to be happening to a young person. The events felt like they were happening out of an expected order of life events; cancer was a disease older people got. The diagnosis, treatment, changes, and challenges for the family should not be happening at this point in their lives. As young women, they ought to be thinking about other matters and doing other things with their time.

We're supposed to be enjoying our new child. This is our first year, you know, new beginnings, the walking, the talking, everything... we're supposed to be having fun doing this. And now look what we have to face. So I was angry at the time. I kind of felt like I had been robbed. (20)

The discovery of the breast abnormality was the first instance where women heard comments made about being too young for cancer. Often, they heard these comments initially from physicians. In retrospect, the women thought this perspective had delayed further investigations for them. The second instance where feeling "out of sync" emerged was in dealing with the side effects of treatment. Fatigue, cognitive difficulties, hair loss, and treatment-induced menopause created a sense of being different than one's friends. No one else in their circle of friends was dealing with hot flashes and difficulty sleeping. These women felt they were aging before their time and their bodies had betrayed them.

I was probably the first one of my circle of friends, or one of the first, where something serious like this would have happened. (18)

...the menopause phenomenon... the pre-aging process (that goes with it) that really changed things for me. That will never get back...I will not be young again... I think that's what I find most difficult. (14)

The residual effects of the chemo, I don't think anyone understands... I didn't feel well for about three years. And it's only now that I've started to feel better. (1)

The third instance where women felt they were "out of sync" occurred when they went searching for services and literature or attended a peer support group. They described discovering that nothing was aimed specifically toward young women. Sitting in a support group of older women as the only younger individual resulted in a sense of isolation. When I found a young woman my age, it was like a lifeline! (11) Frustration could easily bubble up when support group meetings were scheduled for times such as the early evening, the very times when young children needed to be put to bed or older ones needed help with homework. Much of the literature they found on breast cancer did not cover issues such as how to talk with children about cancer, fertility and sexuality as a young woman, or balancing work and family while fighting for your life.

For younger women, the challenges are, for example, day care issues. Even to go to a support group, you have to think about child care... the groups for younger women need to be organized differently than for older women... It's hard in a support group if you are 20 years younger than everyone else. And if they start saying things like, 'I am so glad it didn't happen to me when I was young, it must be so hard for you' or 'at least I have lived my life'. That's not helpful. (24) 
...in the support groups, women would say they were tired from their radiation. They'd go home and nap. And I'm thinking, you know, it's just not an option for a Mum, a Mum with young children. You just have to be up! You have to be on! (12)

These young women found they struggled with the idea of being ill at this point in their lives. The thoughts, "Mothers are not supposed to get sick" or "I don't have time to be sick", were ever present. With so many things happening in the family, with partners' careers, with their own careers, and with growing children, daily life was full of demands. In the role of mother, the women were often at the centre of this activity, keeping everyone organized and making certain everyone was where they needed to be on time (i.e., school, work, etc.). They found their illness could easily throw that family organization into chaos or disarray. Suddenly, family members had to take on new roles and responsibilities.

There is so much going on in our lives... I was sitting in a support group... talking about the cancer stuff... and I'm thinking, 'Oh my God, I have more stuff to worry about than this'. (15)

The untimely nature of illness in these women's lives left them feeling angry, frustrated, and experiencing a sense of being out of control. They felt loss as roles and responsibilities were taken over by others. Guilt became a frequent companion when women saw the roles they thought should rightfully be theirs, as the mother in the household or as a partner in a business, being filled by others. Their ordered world had suddenly changed and had the potential of falling apart. For these women, this was not as it ought to be. The situation left many feeling a sense of isolation and of not fitting in any more.

I'd say it makes me no fun. I take life too seriously... I have to learn to lighten up... to enjoy...I don't know if it's because I'm afraid I won't see tomorrow... I don't laugh a lot...(2)

The young women in this study found themselves wondering who they had become over the course of their breast cancer experience. Once the treatment was over and they began to put their lives back on track, they experienced continuing periods of uncertainty and struggle. The confrontation with mortality and the realization that there is not as much control over life as they had once thought, stimulated reflection about how to live their lives now. Questions such as: Who am I now? What do I need to do? How do I figure this out? and what do I need to change? were commonly raised.

My life, me, I'm a totally different person now... Things that I put a value on before, they don't have value now. (26)

...coming to grips with the fact that you're going to die... I struggle with it off and on... Doing all the things to get my affairs in order... I just never envisioned having to do that at 46! (21)

... work always was a big thing for me, part of who I was... I gained a lot of self-worth through work... cancer has made me reevaluate that. (8)

Thinking about the life-change questions and sorting through the options to find the answers for their own situation was not something these women did entirely alone. Women turned to partners, to friends, to peers in support groups. The task almost seemed to be one of finding a new sense of place or position in the world. One's basic assumptions about self, the roles one plays, and how the world works had been shaken. For some, the process of sorting and sifting through ideas led to a new set of priorities, while for others, it re-affirmed what was of most importance to them. The women described this process of reflection during the time after treatment as an opportunity to clarify and re-establish beliefs, as well as come to terms with the idea that one is being given a second chance.

It really brings into focus your goals and your ambitions and what you want to do with your life. You don't want to wait for tomorrow...you want to do it all right now, just in case. (1)
... everything in life, I don't want to wait for anymore. I want it now. I don't think people, not everyone, can understand that. You don't want to just let life go by. You want to do something with it, because you don't know how much you'll have. (9)

This process of life review and taking stock, important as it is to these women, occurs in the midst of a busy life. The reflection time needed to put the life puzzle together again, and find meaning in why this event had happened to them, as young women, is hard to find within the whirlwind of daily activity. It is also difficult to engage in the process without the necessary support. Partners who perceive that the experience is all behind them and do not want to talk about what has happened can add challenges to the situation. Parents or health care professionals who make comments like, "Just be glad it's over; the cancer's gone," also add to the challenge these young women experience.

\section{Theme: Cancer invaded my whole life}

For the women in this study, life has not been the same since the diagnosis. They see the world differently now. The cancer has touched every aspect of their lives. And the cancer experience cannot be left behind; it has become embedded within their lives. All of their roles-mother, daughter, sibling, partner, employee-have been touched. The very core of their being (Who am I?) has been challenged.

Life goes on at the same time. It's [cancer] got such a big, a great impact on everything... coming to the realization of what's best for you [takes time]. (15)

We make plans... like we normally did before... when the kids graduate... move out... we make all these plans. In my mind, I still have this, "Yeah, if I'm going to be here." (4)

These young women were living within the midst of very busy lives when the cancer was diagnosed and the demands of young families and developing careers will not wait for illness. Life had to go on despite the illness and the daunting demands of treatment. Side effects such as fatigue, nausea or vomiting, or fever, had to be handled within the context of daily living. To have to cope with the side effects and the concerns of day-to-day family living was, at times, overwhelming.

I was very tired. Very, very tired... that affected my role as a mother. Totally, oh, totally... I was so totally frustrated because other people were doing the jobs that I was doing. (12)

...chemotherapy was one of the worst things that I've ever gone through... very sick, tired... not feeling well... depressed... you think it's never going to finish...(16)

For many young women, they tried very hard to keep everything going as it usually did, to decrease the intrusiveness of the cancerrelated demands. But this required a complex balancing or juggling of roles and responsibilities. Women feared they would "drop one of the balls" (3). They sensed they were "on a merry-go-round and would like to get off, but cannot" (13) but, as a mother in the family, others needed them. Resentment about the cancer escalated together with a recognition that the reality of living now had to take the cancer into consideration. They had to learn to live with the fact that cancer had happened to them.

Within the last five years, cancer has become a huge part of our life...but I never let it stop me!... I won't!... As much as I bitch and complain about it, I will not let it stop me. (2)

It just sort of hits you in the face, when you are faced with any kind of cancer. Life is short! It just really grows you up quickly, I think... it changes your outlook. And it makes you strong, and makes you take charge of your life, I think. (9)

You have to adjust. You're not given a chance... you have to learn it's $O K$... to be incapacitated [at times]. (8) 
Yet the activities of a busy family or a growing career are not going to wait for the woman to sort through who she is now and how she will live her life. She is caught in the midst of confusion and chaos, "in a muddle without a map" (5), trying desperately to keep it all going and wishing the cancer experience had not happened. She is balancing multiple roles, all with high expectations from self and others for performance.

It has made it OK, I'm normal... I don't have to be a superwoman and I think that's one of the reasons why breast cancer is so debilitating for so many women, we're expected to juggle every single ball that's thrown at us all at the same time. You have to be a great Mom, you have to be a great wife, you have to be great in bed... you have to have a full-time career and still make sure your whites are white!... being a female in this day and age is not easy. (23)

For many of the young women in this study, their physical body felt different than it had before the treatment. They felt they could not depend on it the same way or feel the same way about it. Some struggled with a sense of disfigurement from the surgery; others had had reconstruction; all had treatment-induced menopause, and confronted questions about fertility and issues regarding sexuality. Knowing where to turn for advice or information on these matters, or finding support and understanding about these types of experiences was a significant challenge for these young women.

... so, I really felt alienated to my body in the sense that I was bald, I had no breast, I still had a huge scar, I had this tube coming out of my chest... and I was nauseated a lot. (12)

I went into menopause and it was like hitting the wall. It was just there, all of a sudden. Periods stopped. And horrible hot flashes. I told one doctor and he said, "That's great". I wasn't impressed... the next week I told another and he just said, "I told you it would happen". Those two things put me in a rage. I just thought, you sons of bitches, you have no idea! I've been told at 40 that I'm not having kids and that I'm going to be sexually dysfunctional, plus I have all these hot flashes and you're not giving me any help. And their idea is that it is not life threatening! (25)

...it's really difficult because, well, I don't know, personally, for me, it has made me feel really old because I have to deal with weight gain, and, of course, I am not having my period any more. And I actually have a couple of age spots for Heaven's sake!... and the hot flashes and the sweating... and the mood swings are wild!...(28)

I had young kids, was on my own. I couldn't find information that was about women my age. Nothing... I mean, what about dating? Or having more children? (17)

Life after cancer treatment also impacted the family. During the early treatment days, family members (partners and children) may have taken on new and different responsibilities. How family life unfolds after the women's initial treatment has finished and she is beginning to feel better can be a struggle. In some measure, the family has been managing without her and may even have expectations about wanting to continue with their new responsibilities. The woman may have expectations about resuming roles and responsibilities or making permanent changes. If there is congruence with all in the family about what ought to happen, there will be less difficulty. For many there is a tension between wanting things to be the same, but realizing that everything feels different.

You know, before you get cancer, you think you've got everything in a nice little box, got it all organized. And you think you've got the answers and everything's okay. And then you get cancer. Not only is everything in the box thrown all over the place, but also nothing fits in it any more. So you have to re-establish, like your beliefs, your thoughts, everything. You have to sort of start over. It's tough. Yeh, it's like you are starting over to some extent. (1)

\section{Discussion}

This study was undertaken to better understand the unique experiences of young women with breast cancer. The richness of the interviews offers poignant insights into the lives of these women and the challenges they faced. Many shared issues similar to those of older women diagnosed with breast cancer (Ferrel, Grant, Funk, Otis-Green, \& Gracia, 1998), but there were also unique perspectives emerging from the context of the young women's lives. Given that the quotations from the interviews (i.e., the voices of the women) speak clearly to the nature of the challenges they faced, the discussion will focus on a few significant observations made by the investigative team linked to practice and future research efforts.

One aspect that stood out in the interviews was the intense drive for staying alive and the passionate stance and emotion behind that drive. This drive was linked on one hand to the women's commitments to children and partners and on the other hand to needs for information and support. The drive for action was aimed at staying alive and meant there was little patience for waiting at any point during the cancer experience, or for not being able to make a decision. The right action needed to be taken immediately to ensure a future in which the women could continue to fulfill roles and responsibilities of importance to them.

Young children and relationships were most often the focus of the important commitments these young women cited. One could argue this is understandable in terms of their stage of development as an adult and within the family unit. Taking action in accord with perceived values and commitments is described in theoretical work by Lazarus and Folkman (1984) on meaning and coping with stressful life events. What is perceived to be "at risk" in a situation drives emotional responses and actions. The practice implication is that cancer nurses need to be sensitive and empathetic to the unique perspectives of these young women patients. They need to find ways to engage in dialogue with the women to uncover what is of importance to them or identify what they perceive as "at risk" if they are ill and not able to do what they normally do. Cancer nurses also need to realize that this perspective is not static; it is dynamic. The conversation needs to happen repeatedly throughout diagnosis, treatment and following treatment, as what is perceived by the women to be "at risk" may change over time.

The women who participated in this study were well educated, articulate in talking about their perspectives, and able to share insights about their needs. All had volunteered to be interviewed, so were comfortable with this form of providing data. One might argue that the sample is limited from these perspectives. However, one could also argue this sample is illustrating characteristics we will observe with increasing frequency as this cohort of women ages and enters the health care system. This cohort has a clearly articulated set of expectations about what good health care is, and an enhanced sense of entitlement for that quality of service. This cohort of women also has the capacity and passion to speak out and not accept what is the status quo if it is not appropriate. Clearly, this has implications for how care is organized, how communication occurs during clinic appointments, how information and support programs are offered, and the range of care and services that need to be provided. Care needs to be person-centred and offered within the context of a family-centred approach.

One of the specific or unique aspects emerging from this study is the critical influence of attitudes and expectations based on the roles of 'being a woman' and 'being a mother'. Once in the mother role, women embrace ideas and attitudes that become part of their expectations about their performance. These expectations have the potential to add to the tensions women feel during a cancer experience - "mothers do not get sick"; "mothers are the centre of all family"; "if I don't do it, it will not get done right"; "I need to put 
the kids/partner first, before myself'. Women described how challenging it was to live up to these expectations and look after themselves at the same time. Resolving the tensions will occur in different ways for different women. However, these tensions need to be considered by cancer nurses and, in some instances, the expectations may need to be challenged and women may need help to do so.

Other unique tensions for which young women may require assistance in finding solutions include the idea of keeping everything normal, protecting others from the reality of cancer, coping with the sense of "being out of sync", and the sense of cancer being unfair and isolating. Since this study was initiated, other investigators have reported how young women find existing services do not fit their needs (Gould, Grassau, Manthorne, Gray \& Fitch, 2006) and that it is difficult for them to find appropriate support. Based on what the women have described, consideration needs to be given to issues like the time support groups are held, availability of child care, and use of

\section{References}

Anderson, D. (1991). The unfinished revolution. Toronto: Doubleday.

Anderson, C.M., \& Stewart, S. (1994). Flying solo: Single women at midlife. New York: N.W. Norton \& Co.

Bilodeau, B.A., \& Degner, L.F. (1996). Informational needs, sources of information and decisional notes in women with breast cancer. Oncology Nursing Forum, 23, 691-6.

Bock, G.H., Bonnema, J., Zwaan, R.E. Vande Velote, C.J., Kievit, J., \& Sigglebout, A.M. (2004). Patients' needs and preferences in routine follow-up after treatment for breast cancer. British Journal Cancer, 90(6), 1144-80.

Brown, M., Koch, T., \& Webb, C. (2000). Information needs of women with non-invasive breast cancer. Journal of Clinical Nursing, 9, 713-722.

Davis, C., Williams, P., Parle, M., Redman, S., \& Turner, J. (2004). Assessing the support needs of women with early breast cancer in Australia. Cancer Nursing, 27(2), 169-174.

Evans, S.B., \& Avis, J.P. (1999). The women who broke all the rules. Naperbille, IL: Sourcebooks Inc.

Ferrell, B.R., Grant, M.M., Funk, B.M., Otis-Green, S.A., \& Gracia, N.J. (1998). Quality of life in breast cancer survivors: Implications for developing support services. Oncology Nursing Forum, 25(4), 887-95.

Finlayson, J. (1995). Against the current. Toronto: Doubleday.

Fitch, M., Beaudoin, G., \& Plewes, L. (2005). How well are sexual concerns of cancer patients addressed: Provider and patient perspectives. Supportive Care in Cancer, 13(6), 24-176 (p. 472).

Fitch, M.I., Bunston, T., \& Elliott, M. (1999). When mom's sick: Changes in a mother's role and in the family after her diagnosis of cancer. Cancer Nursing, 22(1), 58-62.

Gould, J., Grassau, P., Manthorne, J., Gray, R.E., \& Fitch, M.I. (2006). Nothing fit me: Nationwide consultations with young women with breast cancer. Health Expectations, 9, 158-173.

Gray, R.E., Goel, V., Fitch, M.I., Franssen, E., Chart, P., Green, M., et al. (2000). Utilization of professional supportive care services by women with breast cancer. Breast Cancer Research Treatment, 64(3), 353-8.

Hilton, B.A. (1996). Getting back to normal: The family experiences during early stage breast cancer. Oncology Nursing Forum, 23(4), 605-614.

Hilton, B.A., Crawford, J.A., \& Tarko, M.A. (2000). Men's perspectives on individual and family coping with their wives' breast cancer and chemotherapy. Western Journal of Nursing Research, 22, 438-59. technology to connect young women and provide support. Information about fertility, sexuality, and reconstruction are of particular salience to this age group of women and needs to be discussed as part of treatment decision-making. It also needs to be incorporated into survivorship programming. All too often, health care professionals do not inquire about these issues (Fitch, Beaudoin, \& Plewes, 2005).

\section{Summary conclusions}

This study provided clear illustration of unique aspects to the experiences of young women when they are diagnosed and treated for breast cancer. The nature of the challenges they face is linked and influenced by the context of their life situation. Health care professionals need to be aware of the challenges these women face and tailor the provision of information and support to the unique aspects.

Kristjanson, L.J., Chalmers, K.I., \& Woodgate, R. (2004). Information and support needs of adolescent children of women with breast cancer. Oncology Nursing Forum, 31(1), 111-119.

Lazarus, R.S., \& Folkman, S. (1984). Stress, appraisal and coping. New York: Springer.

Lethborg, C.E., Kissane, D., \& Burns, W.I. (2003). It's not the easy part: The experience of significant others of women with early stage breast cancer at treatment completion. Social Work in Health Care, 37(1), 63-85.

Lewis, F.W. (2004). Shifting perspectives: Family-focused oncology nursing research. Oncology Nursing Forum, 31(2), 288-92.

National Cancer Institute of Canada. (2006). Canadian cancer statistics. Toronto, ON: Author.

Nissen, M.J., Swanson, K.K., \& Kind, E.A. (2002). Quality of life after post mastectomy breast reconstruction. Oncology Nursing Forum, 29(3), 547-53.

Ontario Breast Cancer Information Exchange Partnership. (2003). Promoting regional and local capacity for breast cancer information and support: Final report. Retrieved from http://www.obciep.on.ca

Ontario Breast Cancer Information Exchange Project (2001). Community capacity building project: promoting regional/local capacity for breast cancer information dissemination and provision of support in Ontario. Unpublished manuscript.

Quinn-Beers, J. (2001). Attachment needs of adolescent daughters of women with breast cancer. Journal of Psychosocial Oncology, 19(1), 35-48.

Raupach, J.C., \& Hiller, J.E. (2002). Information and support of women following the primary treatment of breast cancer. Health Expectations, 5(4), 289-301.

Rees, C.E., \& Bath, P.A. (2000). The information needs and source preferences of women with breast cancer and their family members. Journal of Advanced Nursing, 31, 833-41.

Rondle, K. (1997). Survivorship and breast cancer: The psychosocial issues. Journal of Clinical Nursing, 6, 403-10.

Silverman, D. (2000). Doing qualitative research: A practical handbook. London: Sage Publications.

Trussler, T. (Ed.). (2001). Uncovering the gaps: An inquiry of breast care in British Columbia. Vancouver: Canadian Breast Cancer Foundation - B.C. Chapter.

Turner, J. (1990). Living the changes. Winnipeg: University of Manitoba Press.

Yates, P. (1999). Family coping: Issues and challenges for cancer nursing. Cancer Nursing, 22(1), s63-71. 